\title{
Prevalence of Risk Factors of Under-Nutrition Among Children 1 to 5 Years in Eastern, Sri Lanka
}

\author{
Thilini Herath ${ }^{1, *}$, Josepha Joseph ${ }^{2}$ \\ ${ }^{1}$ Department of Primary Health Care, Faculty of Health-Care Sciences, Eastern University, Batticaloa, Sri Lanka \\ ${ }^{2}$ Department of Supplementary Health Sciences, Faculty of Health-Care Sciences, Eastern University, Batticaloa, Sri Lanka \\ Email address: \\ herathhmtp@gmail.com (T. Herath), josepha_joseph@yahoo.com (J. Joseph) \\ ${ }^{*}$ Corresponding author
}

\section{To cite this article:}

Thilini Herath, Josepha Joseph. Prevalence of Risk Factors of Under-Nutrition Among Children 1 to 5 Years in Eastern, Sri Lanka. Journal of Food and Nutrition Sciences. Vol. 4, No. 4, 2016, pp. 103-107. doi: 10.11648/j.jfns.20160404.15

Received: May 30, 2016; Accepted: June 8, 2016; Published: July 18, 2016

\begin{abstract}
Global studies have shown that under-nutrition, results for at least half of all childhood death worldwide and it has identified as a major cause of morbidity and mortality in children under five years of age. According to the UNICEF conceptual framework, there is a multifactorial causality for under-nutrition. The objective of this study was to assess the prevalence of risk factors of under-nutrition among children aged one to five years in the Batticaloa Medical Officer of Health area in Eastern province of Sri Lanka. A cross-sectional study was carried out among 1-5 year old in the Batticaloa Medical Officer of Health area $(n=500)$ recruited using multistage cluster sampling method. Data were collected from mothers by using an interviewer administered questionnaire. Data were analyzed by using descriptive statistics using SPSS V20. More than $50 \%$ of the children had gotten infections during past two weeks prior to the data collection and had an exposure to child abuse. Similarly, more than $50 \%$ of the children had parents whose education levels up to primary or less, a father who consumes alcohol and a mother who exposed to intimate partner violence. The majority of mothers (more than 50\%) showed a satisfactory level of knowledge on essential nutrients to the child. But, in contrast to that, a similar percentage of the children were fed animal source food, legumes, dark green leaves, yellow color vegetables and yellow color fruits one time per day. Nutrition interventions should be targeted on high prevalent factors and further research is needed to investigate the causes of knowledge and practice gap in relation to child feeding.
\end{abstract}

Keywords: Under-Nutrition, Risk Factors, Sri Lanka

\section{Introduction}

Global studies have shown that under-nutrition, results for at least half of all childhood death worldwide [1-3]. Consequences of under-nutrition are ranged from growth failure, intellectual impairment and lower resistance to infections to risk to develop some chronic disease [4]. Hence this has been recognized as a leading cause of death, disability, and ill health among children under five years and thus this problem is a vital challenge to public health and global development [5-7]. South Asia has the highest levels of underweight affecting $46 \%$ of all under 5 children in the region [8]. A literature review on under-nutrition in Sri Lanka reveals that the prevalence of underweight, stunting and wasting levels are $21.2 \%, 17.3 \%$ and $14.7 \%$, respectively [9] and it considers as a significant public health problem in Sri Lanka despite other maternal and child health indicators reported good achievements in the recent past.

According to the UNICEF conceptual framework, there is a multifactorial causality for under-nutrition [10]. These factors range from child related factors to wider societal factors. However, the magnitude of these risk factors of under-nutrition among under five children vary across different local settings. Therefore, it is a prompt response to assess the problem at community level using a community based descriptive cross sectional study to determine the prevalence of risk factors. So this determination will be an important measure to design appropriate locally relevant strategies which can be helpful in reducing the problem. Further, available research evidence on under-nutrition in Sri 
Lanka is limited to prevalence estimates and analytical studies. Though there are few national studies those also had done by excluding both North and Eastern provinces due to the prolonged civil war.

So, given the lack of research studies on risk factor prevalence of child under-nutrition in Eastern province, we conducted the present study to assess the prevalence of risk factors of under-nutrition among children aged 1 to 5 years in the Batticaloa Medical Officer of Health $(\mathrm{MOH})$ area in Eastern province of Sri Lanka. This study will be useful for the Sri Lankan public health system to sanitize potential health disparities and their magnitude by planning appropriate, effective and sustainable health promotion interventions to achieve health equity.

\section{Materials and Methods}

A cross sectional study was carried out from January 2015 to December 2015 in the Batticaloa $\mathrm{MOH}$ area. The study population consisted of children aged one to five years and their mothers. The total sampling frame was approximately 6650 [11]. The sample size required to estimate a prevalence of 17.5\% (Demographic and Health Survey 2006/07, [9] had found this figure for stunting among children under five years in Sri Lanka), with a 95\% confidence interval. The exact sample size of this study was 443 according to the WinPepi statistical software (version 2.68) by considering the sampling method as cluster sampling, acceptable difference 0.05 and design effect as 2. According to the calculation 30 clusters were needed with a cluster size of 15 to achieve the calculated sample size. A field weighing post was considered as a cluster for this study. So the total sample size was $450(30 * 15)$ for this study. A final sample size of 495 was calculated after adjusting for an estimated non response rate of $10 \%$. This value was rounded to 500 . A multi stage sampling technique was carried out to select the sample. Exclusion criteria included genetic disorders and chronic medical conditions for the child and psychiatric disorders and disability of the mother. Birth \& immunization register (EPI 379) maintained by the Public Health Midwife (PHM) was used to select children randomly within the selected cluster. The data were collected from the mother of the selected child at their homes. The mothers of the children were informed about the purpose of the study and invited to participate through the PHM of the selected area. Prior notice was given before visiting in their homes and two attempts were taken if the mother was unable to meet.

A pretested validated interviewer administered questionnaire, developed by the investigators was used to obtain data on selected risk factors based on the past global and local literature. This study examined prevalence of following risk factors. Socioeconomic factors: mother's education level up to primary or less, father's education level up to primary or less, a monthly family income below 25,000 rupees; Dietary factors: a period of exclusive breast feeding less than 6 months, commencement of complementary feeding after 7 months, feeding practices on the selected child; Child factors: a birth weight below $2.5 \mathrm{~kg}$, infections during past 2 weeks, exposure of the child to abuse; Maternal factors: multiple birth, mother's age below 22 years at child birth, mother's knowledge on child nutrition, maternal exposure to Intimate Partner Violence (IPV); Household factors: extended family set up, more than 2 under five children per household, not having mass media exposure, tobacco smoking father, alcohol consuming father. Child health development record was used to gather secondary data on infant's birth factors including birth weight. Trained data collectors were used to interview the mothers. Descriptive statistics were used to do the statistical analysis by using the Statistical Package for Social Science (SPSS version 20).

Ethical approval for conducting the study was granted from the ethical review committee of the Faculty of HealthCare Sciences, Eastern University. Informed written consent was obtained from mothers of the selected child prior to data collection. Standard measures were taken to ensure confidentiality of data.

\section{Results}

The response rate was $100 \%$ in this study and probably due to support from the PHMs for the data collection process.

\subsection{Characteristics of the Study Population}

Of the 500 children, about $33.5 \%$ of the children were belonged to 12-23 months age group and the mean age of the study population was 31.38 months (SD +/- 12.9) and 52.6\% were females. Most of the children were Sri Lankan Tamils $(88.4 \%)$ (Table 1).

Table 1. Distribution of the basic socio demographic characteristics of study sample.

\begin{tabular}{lll}
\hline Socio-demographic characteristic & $\begin{array}{l}\text { Number } \\
\text { (Total=500) }\end{array}$ & Percent \\
\hline Age in months & & \\
$12-23$ & 168 & 33.5 \\
$24-35$ & 150 & 29.9 \\
$36-47$ & 111 & 22.2 \\
$48-59$ & 71 & 14.2 \\
Sex & & \\
Female & 263 & 52.5 \\
Male & 237 & 47.3 \\
Ethnicity & & \\
Sinhala & 2 & 0.4 \\
Sri Lankan Tamil & 443 & 88.4 \\
Indian Tamil & 5 & 1.0 \\
Sri Lankan Moors & 12 & 2.4 \\
Muslim & 38 & 7.6 \\
\hline
\end{tabular}

\subsection{Prevalence of Risk Factors of Under Nutrition}

This study considered 18 risk factors which were selected from past literature. More than $50 \%$ of the children's parents educated up to primary or less. But the exclusive breastfeeding rate for first 6 months was good and there were only $2.4 \%$ of mothers who didn't follow the standard feeding 
practice on breast feeding. Low birth weight rate was $16.8 \%$. There were more than $50 \%$ children who got infections during the past 2 weeks prior to the data collection and had an exposure to child abuse. More than $50 \%$ of the children had a father who consumes alcohol and a mother who exposed to IPV (Table 2).

Table 2. Prevalence of risk factors of under nutrition among the sample.

\begin{tabular}{|c|c|c|c|}
\hline Risk factor category & Risk factor & Number Total (500) & Percent \\
\hline \multirow{3}{*}{ Socioeconomic } & Mother's education level up to primary or less & 322 & 64.3 \\
\hline & Father's education level up to primary or less & 335 & 66.9 \\
\hline & A monthly income below 25,000 rupees & 224 & 44.9 \\
\hline \multirow{2}{*}{ Dietary } & A period of exclusive breastfeeding less than 6 months & 12 & 2.4 \\
\hline & Commencement of complementary feeding after 7 months & 211 & 42.1 \\
\hline \multirow[b]{2}{*}{ Child } & A birth weight below $2.5 \mathrm{~kg}$ & 84 & 16.8 \\
\hline & Infections during past 2 weeks & 280 & 55.5 \\
\hline \multirow{3}{*}{ Maternal } & Multiple birth & 1 & 0.2 \\
\hline & Mothers age below 22 years at child birth & 103 & 20.6 \\
\hline & Maternal exposure to IPV & 332 & 66.3 \\
\hline \multirow{4}{*}{ Household } & Extended family set up & 115 & 23 \\
\hline & More than 2 under 5 children per household & 33 & 6.6 \\
\hline & Not having mass media exposure & 45 & 9.0 \\
\hline & Tobacco smoking father & 160 & 31.9 \\
\hline
\end{tabular}

\subsection{Knowledge Among Mother's on Children Nutrition}

Table 3 shows that the knowledge of the mother on each essential nutrient to child was satisfactory. Most of the mothers (85.2\%) knew that iron is essential and 67.9\% mothers had the ability to name at least two iron source foods. Though $69.7 \%$ of mothers knew that vitamin A is essential to the child only $18 \%$ of the mothers had the ability to name at least two vitamin A sources. Similarly, only $25.1 \%$ of the mothers had the ability to name at least two calcium sources, though $71.5 \%$ mothers had the knowledge of the calcium requirement of the child.

Table 3. Knowledge among mother's on children nutrition.

\begin{tabular}{lll}
\hline Knowledge Category & Number Total (500) & Percent \\
\hline Knowing about essential nutrients & & \\
Iron & 427 & 85.2 \\
Calcium & 358 & 71.5 \\
Vitamin A & 349 & 69.7 \\
Protein & 442 & 88.2 \\
Carbohydrate & 449 & 89.6 \\
Ability to recognize at least 2 food & & \\
sources of the following & & \\
Iron & 340 & 67.9 \\
Calcium & 126 & 25.1 \\
Vitamin A & 90 & 18.0 \\
Protein & 288 & 57.5 \\
Carbohydrate & 317 & 63.3 \\
\hline
\end{tabular}

\subsection{Feeding Practices of the Selected Children}

Most of the children (66.9\%) were given animal source food for one time per day. Similarly, most of the children fed legumes $(71.5 \%)$, dark green leave $(60.7 \%)$, yellow color vegetables $(66.9 \%)$, and yellow color fruits $(75 \%)$ one time per day. Most of the children (79.4\%) were not fed nuts and seeds for following day. But $51.7 \%$ children consume high salty instant food frequently and $43.7 \%$ children consume sugar dense food frequently (Table 4).
Table 4. Feeding practices on the selected children.

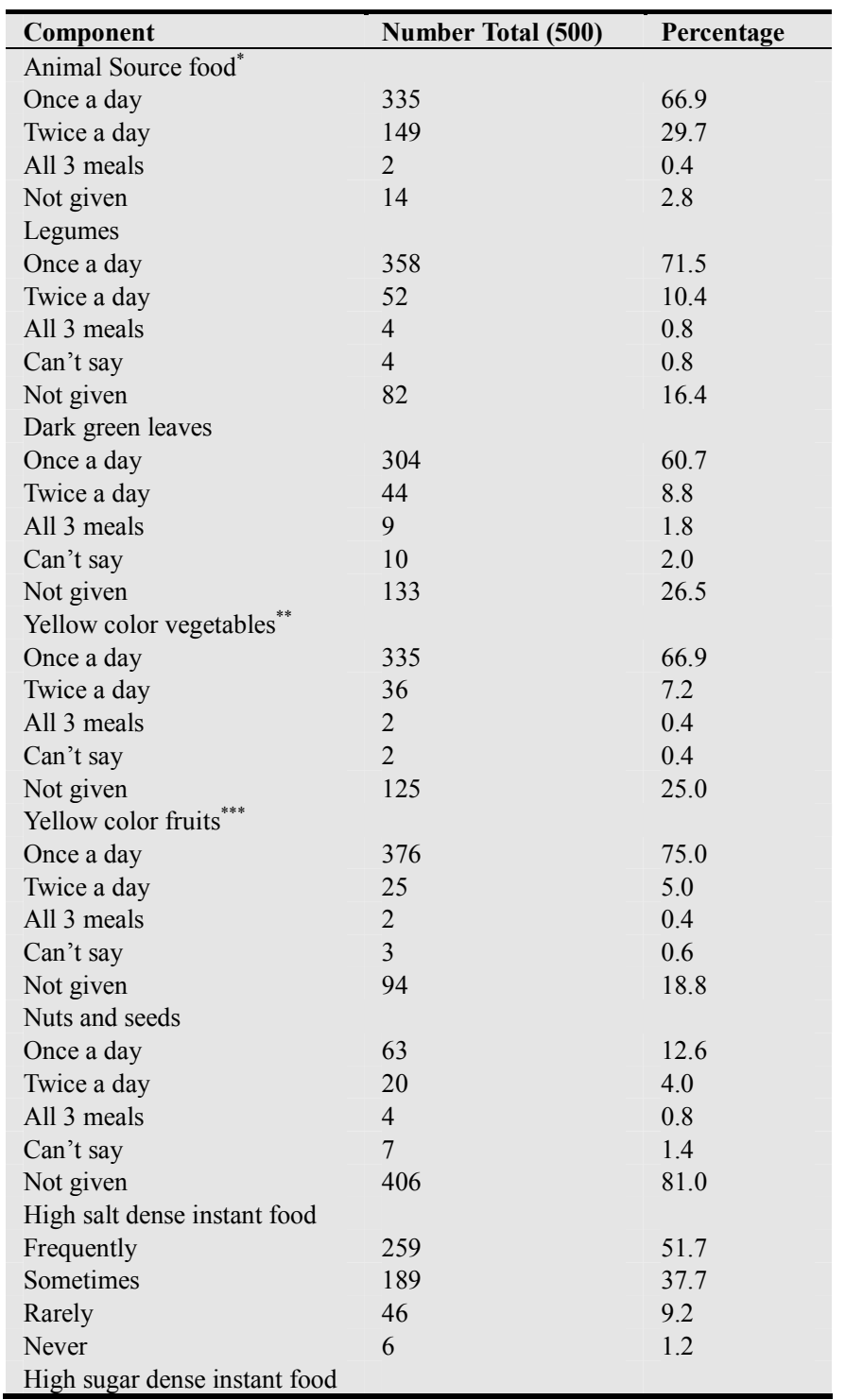




\begin{tabular}{lll}
\hline Component & Number Total (500) & Percentage \\
\hline Frequently & 219 & 43.7 \\
Sometimes & 255 & 50.9 \\
Rarely & 22 & 4.4 \\
Never & 04 & 0.8 \\
\hline
\end{tabular}

*Fish/Meat/egg

**Pumpkin/Carrot/Yellow Sweet Potatoes

***Papaya/Mango

\section{Discussion}

Our findings are not directly comparable with previous studies conducted in Sri Lanka as no study had been done to assess prevalence of risk factors of under-nutrition. Also, our study sample was not limited to children from birth to two years as most of the local studies had been done, though birth to two years is the critical age for future growth, health and development of the child [10]. We can discuss our study findings in a light of some limitations. Our study was cross sectional in nature and it was limited to one $\mathrm{MOH}$ area. This would reduce the potential of generalizing the findings to the whole district. Further, this study didn't evaluate the nutritional indicators and statistically significant factors for causing under-nutrition in the Batticaloa $\mathrm{MOH}$ area. Even though current feeding practices were assessed, our study was not used World Health Organization recommended Infant and Young Child Feeding (IYCF) guidelines to assess feeding practices of the child between 12-23 months. So the study findings can't be compared with studies which used these guidelines.

Our data indicate more than $50 \%$ of the children had parents whose education level up to primary or less. According to several studies maternal education plays a major role and it has a positive impact on reducing child under-nutrition [1215]. Father's education level is also an important risk factor because in the Sri Lankan context usually father is the bread winner and decision maker of a family $[12,13]$. According to our data, $44.9 \%$ of the sample belong to a monthly income less than 25,000 rupees. Monthly income is also an important factor because it decides purchasing power of goods. There should be policy level decisions to upgrade the education level of the people and also to enhance their sources of earnings since Batticaloa is a war affected district before 10 years. The health system of Sri Lanka should consider above in developing locally relevant preventive strategies for reducing child under-nutrition.

According to our study more than $50 \%$ of fathers consumed alcohol and mothers exposed to IPV. The prevalence of IPV among mothers of under 5 in Bangladesh in $2014(49.6 \%)$ was lower than that for Batticaloa $\mathrm{MOH}$ area $(66.3 \%)$ [16]. Our data indicate a lower prevalence of paternal tobacco smoking $(31.9 \%)$ than that of Bangladesh during 1996-2006 (49\%) [17]. Preventive strategies should also be focused on these types of social causes rather not only focusing on the direct causes since those prevalence values are high. Our data also show that more than $50 \%$ of under 5 children had exposed to child abuse and got infections during the past 2 weeks prior to the data collection. These findings indicate two contrast aspects, the former one being neglected while the latter one is always taken into consideration in preventive activities within Sri Lanka. Further studies are needed to find out possible root causes while health interventions are going on to control the effects of these.

Contrast to data published by Peiris and Wijesinghe [18], our study showed a satisfactory level of knowledge regarding essential nutrients for the under 5 children. The high level of knowledge of Iron, Vitamin A and Calcium may be a result of nutrition counseling of PHMs and because of the updates getting through the mass media. But in Peiris and Wijesinghe, have been reported that maternal knowledge regarding micronutrients was poor among his study sample in Weeraketiya $\mathrm{MOH}$ area which is similar in economic and demographic characteristics in the Batticaloa $\mathrm{MOH}$ area. Though the people have exposed to conflicts, current health education work by multiple sectors might contribute to high level of knowledge among Batticaloa mothers compared with Weeraketiya mothers in 2010 . Same reason can be used to justify the result of having a good rate of exclusive breastfeeding during the first 6 months among the sample.

Our study showed a $16.8 \%$ of low birth weight rate among the children and according to past studies lower birth size is significantly associated with under-nutrition in early childhood [12, 13, 19-22].

In this study, we have shown that dietary diversity is poor among aged 1 to 5 year old children in the Batticaloa $\mathrm{MOH}$ area because of the mother's current feeding practices. But nearly $50 \%$ of children are consuming high salt and sugar dense instant food frequency. Similarly, Bandara et al [23] has also stated that the proportion of infants aged 6-8 months who consumed eggs, fruits and vegetables other than those rich in vitamin A and flesh foods was low in Sri Lanka. Further Senarath et al [24] in his study, which considered only 6-23 months children, has reported that complementary feeding indicators were adequate except in the 6-11 months age group and he recommended that subgroups with inappropriate feeding practices should be the focus of IYCF promotion programs. These results showed the urgent need for timely interventions up on the changing trends of causes of under- nutrition due to rapid urbanization.

The above findings are verified the knowledge on possible causes of childhood under-nutrition and help policy makers to develop locally relevant strategies. Government should also take necessary steps in educating and empowering under 5 families in taking actions towards reducing this issue by improving their capacities on high prevalent risk factors despite of the traditional health education programs.

\section{Conclusion}

Future prevention interventions should be targeted specially for upgrading education level, reducing low birth weight rate, managing infections and reducing alcohol consumption by fathers, preventing child abuse and IPV since they reported a high prevalence rate than other risk 
factors in the Batticaloa $\mathrm{MOH}$ area. Further studies are needed to find out the causes of knowledge and practice gap in relation to child feeding.

\section{Acknowledgement}

Our gratitude extends to Eastern University, Sri Lanka for providing financial support to conduct this study. We convey our gratitude to all study participants who participated enthusiastically in this study. We are also grateful for the extensive cooperation provided by the Regional Director of Health Services / Batticaloa, Medical Officer of Health / Batticaloa $\mathrm{MOH}$ area and Public Health Midwives.

\section{References}

[1] Demissie S, Worku A. Magnitude and Factors Associated with Malnutrition in Children 6-59 Months of Age in Pastoral Community of Dollo Ado District, Somali Region, Ethiopia. Sci J Public Health. Vol. 1, 2013, pp. 175-83. Do: 10.11648/j. sjph. 20130104.12.

[2] Meshram II, Arlappa N, Balakrishna N, Rao KM, Laxmaiah A, Brahmam GNV. Trends in the prevalence of undernutrition, nutrient and food intake and predictors of undernutrition among under five year tribal children in India. Asia Pac J Clin Nutr. Vol. 21, 2012, pp. 568-76.

[3] Rice AL, Sacco L, Hyder A, Black RE. Malnutrition as an underlying cause of childhood deaths associated with infectious diseases in developing countries. Bulletin of the World Health Organization. Vol. 78, 2000, pp. 1207-1221.

[4] Girmay et al. Prevalence and predictors of undernutrition among infants aged six and twelve months iButajira, Ethiopia. PMaMiE Birth Cohort BMC Public Health. Vol. 10, 2010, p. 27.

[5] Arthur SS, Nyide B, Soura AB, Kahn K, Weston M, Sankoh O. Tackling malnutrition: a systematic review of 15-year research evidence from INDEPTH health and demographic surveillance systems. Global Health Action. Vol. 8, 2015 p. 28298.

[6] Masibo PK, Makoka D. Trends and determinants of undernutrition among young Kenyan children: Kenya Demographic and Health Survey; 1993, 1998, 2003 and 20082009. Public Health Nutr. Vol. 15, 2012, pp. 1715-27. Do: $10.1017 / \mathrm{s} 1368980012002856$.

[7] Pasricha SR, Biggs BA. Undernutrition among children in South and South-East Asia. J Paediatr Child Health. Vol. 46, 2010, pp. 497-503. Do: 10.1111/j. 1440-1754.2010.01839. x.

[8] Khan AA, Bano Nazil, Salam Abdus. Child malnutrition in South Asia: A comparative perspective. South Asian Survey. Vol. 14, 2007, pp. 129-145.

[9] Department of Census and Statistics (DCS) and Ministry of Healthcare and Nutrition (MOH). Sri Lanka Demographic and Health Survey 2006-07. Colombo, Sri Lanka, 2009. Retrieved May $30 \quad 2015, \quad$ from www.statistics.gov.lk/social/DHS\%20200607\%20FinalReport.pdf

[10] UNICEF, The right ingredients: the need to invest in child nutrition, 2013. Retrieved January 20 2016, from https://www.unicef.org.uk/Documents/Publicationpdfs/UNICEFUK ChildNutritionReport2013w.pdf

[11] Department of Census and Statics (DCS) Sri Lanka. District Statistical Hand Book. 2010. Retrieved May 30 2015, from http://www.statistics.gov.lk/DistrictStatHBook.asp?District=B atticaloa

[12] Sujendran S, Senarath U, Joseph J. Prevalence of Stunting among Children Aged 6 to 36 Months, in the Eastern Province of Sri Lanka. Nutr Disorders Ther. Vol. 5, 2015, pp. 2-6.

[13] UNICEF, State of the world's children. New York: Oxford University Press, 1998.

[14] Islam MA, Rahman MM, Mahalanabis D. Maternal and socioeconomic factors and the risk of severe malnutrition in a child: a case-control study. European Journal of Clinical Nutrition. Vol. 48, 1994, pp. 416-424.

[15] Smith LC, Haddad L. Explaining Child Malnutrition in Developing Countries: A Cross- Country Analysis.' Research Report 111, International Food Policy Research Institute, Washington D.C, 2001.

[16] Ziaei S, Naved RT, Ekström EC. Women's exposure to intimate partner violence and child malnutrition: findings from demographic and health surveys in Bangladesh. Matern Child Nutr. Vol. 10, 2014, pp. 347-59.

[17] Chowdhury F, Chisti MJ, Hossain MI, Malek MA, Salam MA, Faruque AS. Association between paternal smoking and nutritional status of under five children attending Diarrhoeal Hospital, Dhaka, Bangladesh. Acta Paediatrica. Vol. 100, 2011, pp. 390-5.

[18] Peiris TDR, Wijesinghe DGNG. Status of under 5 Year-Old Children and its Relationship with Maternal Nutrition Knowledge in Weeraketiya DS division of Sri Lanka. Tropical Agricultural Research. Vol. 21, 2010, pp. 330-339.

[19] Rannan-Eliya RP, Hossain SMM, Anuranga C, Wickramasinghe R, Jayatissa R, Abeykoon A T P L. Trends and determinants of childhood stunting and underweight in Sri Lanka. Ceylon Medical Journal. Vol. 58, 2013, pp. 10-18.

[20] Rayhan I, Khan MSH. Factors Causing Malnutrition among under Five Children in Bangladesh. Pakistan Journal of Nutrition. Vol. 5, 2006, pp. 558-562.

[21] Ahmed T, Islam S. Impact of Socioeconomic Condition and Maternal Education on Nutritional Status of Children. Dhaka Shishu Hospital J. 1984, pp. 1-6.

[22] Bairagi R, Chowdhury MK. 'Socio-economic and anthropometric status and mortality of young children in rural Bangladesh.' Int. J. Epidemiol. Vol. 23, 1994, pp. 1197-1281.

[23] Bandara T, Hettiarachchi M, Liyanage C, Amarasena S. Current infant feeding practices and impact on growth in babies during the second half of infancy J Hum Nutr Diet, 2014.

[24] Senarath U, Godakandage SS, Jayawickrama H, Siriwardena I, Dibley MJ. Determinants of inappropriate complementary feeding practices in young children in Sri Lanka: secondary data analysis of Demographic and Health Survey 2006-2007. Matern Child Nutr. Vol. 8, 2012, pp. 60-77. 